\title{
Cross-track Infrared Sounder (CrIS) satellite observations of tropospheric ammonia
}

\author{
M. W. Shephard ${ }^{1}$ and K. E. Cady-Pereira ${ }^{2}$ \\ ${ }^{1}$ Environment Canada, Toronto, Ontario, Canada \\ ${ }^{2}$ Atmospheric and Environmental Research, Inc., Lexington, MA, USA \\ Correspondence to: M. W. Shephard (mark.shephard@ec.gc.ca)
}

Received: 23 September 2014 - Published in Atmos. Meas. Tech. Discuss.: 19 November 2014

Revised: 22 February 2015 - Accepted: 5 March 2015 - Published: 19 March 2015

\begin{abstract}
Observations of atmospheric ammonia are important in understanding and modelling the impact of ammonia on both human health and the natural environment. We present a detailed description of a robust retrieval algorithm that demonstrates the capabilities of utilizing Crosstrack Infrared Sounder (CrIS) satellite observations to globally retrieval ammonia concentrations. Initial ammonia retrieval results using both simulated and real observations show that (i) CrIS is sensitive to ammonia in the boundary layer with peak vertical sensitivity typically around $\sim 850$ $750 \mathrm{hPa}(\sim 1.5$ to $2.5 \mathrm{~km})$, which can dip down close to the surface $(\sim 900 \mathrm{hPa})$ under ideal conditions, (ii) it has a minimum detection limit of $\sim 1$ ppbv (peak profile value typically at the surface), and (iii) the information content can vary significantly with maximum values of $\sim 1$ degree-of-freedom for signal. Comparisons of the retrieval with simulated "true" profiles show a small positive retrieval bias of $6 \%$ with a standard deviation of $\sim \pm 20 \%$ (ranging from \pm 12 to $\pm 30 \%$ over the vertical profile). Note that these uncertainty estimates are considered as lower bound values as no potential systematic errors are included in the simulations. The CrIS $\mathrm{NH}_{3}$ retrieval applied over the Central Valley in CA, USA, demonstrates that CrIS correlates well with the spatial variability of the boundary layer ammonia concentrations seen by the nearby Quantum Cascade-Laser (QCL) in situ surface and the Tropospheric Emission Spectrometer (TES) satellite observations as part of the DISCOVER-AQ campaign. The CrIS and TES ammonia observations show quantitatively similar retrieved boundary layer values that are often within the uncertainty of the two observations. Also demonstrated is CrIS's ability to capture the expected spatial distribution in the ammonia concentrations, from elevated values in the
\end{abstract}

Central Valley from anthropogenic agriculture emissions, to much lower values in the unpolluted or clean surrounding mountainous regions. These initial results demonstrate the capabilities of the CrIS satellite to measure ammonia.

\section{Introduction}

Ammonia, along with ammonium nitrate and ammonium sulfate aerosols, is important for the nitrogen cycle that directly or indirectly impacts air quality, water quality and the climate. In the atmosphere ammonia is a toxin, and it combines with sulfates and nitric acid to form ammonium nitrate and ammonium sulfate, which constitute $\sim 50 \%$ of the mass of fine particulate matter $\left(\mathrm{PM}_{2.5}\right)$ over land (e.g. Seinfeld and Pandis, 1988). These particles form smog and, in addition to being statistically associated with health impacts, such as bronchitis, asthma, cardiovascular disease and lung disease, cause premature deaths (Schwartz et al., 2002; Reiss et al., 2007; Pope et al., 2002, 2009; Crouse et al., 2012). For example, there is a 6 and $8 \%$ increase in the risk of cardiopulmonary and lung cancer mortality associated with exposure to $10 \mu \mathrm{g} \mathrm{m}^{-3}$ increases in $\mathrm{PM}_{2.5}$ concentrations (Pope et al., 2002). In terms of climate change, ammonia's contribution to atmospheric aerosols (ammonium) has both a direct (reflection of solar radiation) radiative forcing effect of $\sim-0.35 \mathrm{~W} \mathrm{~m}^{-2}$ since pre-industrial times, and a potentially larger indirect (clouds) radiative forcing effect (e.g. Charlson et al., 1991; Myhre et al., 2013). Furthermore, reactive nitrogen $(\mathrm{Nr})$ (e.g. ammonia $\left(\mathrm{NH}_{3}\right)$, ammonium $\left(\mathrm{NH}_{4}\right)$, nitrogen oxide (NO)) has increased by a factor of 2 to 5 over the last century (Reay et al., 2008; Lamarque et al., 2010), 
and anthropogenic ammonia gas emissions (i.e. concentrated animal feeding operations (CAFO), fertilizers, biofuel) are one of the IPCC AR5 Representative Pathway Concentration (RPC) species predicted to increase in the future (Lamarque et al., 2011; Ciais et al., 2013). Increasing atmospheric concentrations of ammonia have the potential to increase the global deposition of reactive nitrogen to nitrogen-poor ecosystems, which in turn increases the efficiency of the land and ocean in removing human-induced carbon dioxide from the atmosphere, thus acting as a carbon sink ("carbon dioxide fertilization effect" (Reay et al., 2008)). Excess deposition in terrestrial ecosystems leads to soil acidification and loss of biodiversity (e.g. Carfrae et al., 2004); and in coastal ecosystems causes eutrophication, algal blooms, and loss of fish and shellfish (e.g. Paerl et al., 2002). In spite of the significant role ammonia plays in our environment and health, there is still limited knowledge of the magnitude and seasonal/spatial distribution of $\mathrm{NH}_{3}$ emission sources, especially on a global scale. Therefore, satellite observations of ammonia provide an unprecedented opportunity to gain a greater understanding of atmospheric ammonia concentrations and to constrain model emission, which are still poorly known, especially outside of North America and Europe.

Observations from the NASA Aura Tropospheric Emission Spectrometer (TES) (Beer et al., 2001) Fourier Transform Spectrometer (FTS) launched on 15 July 2004, and the Infrared Atmospheric Sounder Interferometer (IASI) (Clerbaux et al., 2009) FTS launched on MetOp-A (19 October 2006) and MetOp-B (17 September 2012), have demonstrated the value of lower tropospheric ammonia satellite measurements. For example, IASI and TES observations have shown spatial and seasonal distributions of ambient tropospheric ammonia concentrations globally (Clarisse et al., 2009; Shephard et al., 2011; Van Damme et al., 2014a) and regionally (Beer et al., 2008; Clarisse et al., 2010). Also, combining these satellite ammonia emissions with coincident satellite observations of carbon monoxide has shown the potential of using the satellite-derived $\mathrm{NH}_{3}$ : $\mathrm{CO}$ enhancement ratios to identify the ammonia emission sources and constrain $\mathrm{NH}_{3}$ emission inventories (e.g. Luo et al., 2015). These satellite observations have been initially evaluated with in situ ammonia surface observations. Comparisons of instantaneous twice daily satellite boundary layer averaged observations with footprints on the order of $5-15 \mathrm{~km}$ with commonly measured in situ bi-weekly averaged surface network observations can be challenging given the obvious sampling differences (horizontal, temporal, and vertical). Nevertheless, Pinder et al. (2011) was able to show that the TES ammonia observations reflect spatial gradients and seasonal trends when compared with overlapping bi-weekly CAMNet in situ surface observations. Similar evaluations of the IASI $\mathrm{NH}_{3}$ column retrievals have been performed using indirect surface and aircraft comparisons (Van Damme et al., 2014a).

Satellite observations of tropospheric ammonia are also contributing to better understanding of the ammonia emis- sion inventories used in chemical transport models. Both IASI and TES satellite observations have been used to evaluate and improve ammonia emissions and transport in global (GEOS-Chem) and regional chemistry transport (Community Multiscale Air Quality (CMAQ)) models, which have been broadly under-predicting ammonia concentrations compared to the satellite observations, especially in large source regions like the central valley in California, USA. Some examples include using TES ammonia observations to provide top-down constraints on $\mathrm{NH}_{3}$ emissions in GEOS-Chem (Zhu et al., 2013). Heald et al. (2012) used IASI observations along with the GEOS-Chem chemical transport model to show that $\mathrm{NH}_{3}$ is likely underestimated in California, leading to a local underestimate of ammonium nitrate aerosol. At the same time, Walker et al. (2012) using TES observations showed a similar under-prediction of ammonia emissions by GEOS-Chem over California, which has among the largest concentrations of ammonia in the USA. TES satellite and in situ observations were also used to evaluate the new treatment of ammonia bidirectional fluxes in the CMAQ and GEOS-Chem models (Zhu et al., 2015). In addition, insights into the diurnal variability of animal $\mathrm{NH}_{3}$ emissions have been obtained by combining TES satellite with in situ ground-based and aircraft observations in order to develop and evaluated a new improved $\mathrm{NH}_{3}$ temporal emissions profile for CMAQ (Bash et al., 2013, 2015).

While these initial studies have greatly improved our knowledge of the magnitude, seasonal cycle and spatial distribution of $\mathrm{NH}_{3}$ emissions, there still remain large uncertainties in ammonia emissions and in the nitrogen cycle in general. Therefore, advancements in our understanding of ammonia emission around the globe will benefit from recent and new satellite ammonia observations. The Crosstrack Infrared Sounder (CrIS) instrument is a FTS operated by the USA NOAA/NASA/DoD Joint Polar Satellite System (JPSS) program on Suomi National Polar-orbiting Partnership (NPP) satellite, which was launched on 28 October 2011. With its good radiometric calibration and instrument signal-to-noise ratio (SNR), CrIS also has the potential to globally monitor ammonia and to contribute to a better understanding of tropospheric ammonia variability over the globe. The overall objective of this analysis is to demonstrate the capability of the CrIS instrument to retrieve atmospheric ammonia. We present (i) the CrIS ammonia retrieval strategy including spectral microwindows and error analysis, (ii) simulations showing the retrieval vertical sensitivity, level-ofdetectability, and performance, (iii) the example of the first CrIS observations of elevated ammonia over the Central Valley of California, USA, and (iv) initial comparison of these CrIS $\mathrm{NH}_{3}$ retrievals with coincident TES satellite and Quantum Cascade-Laser (QCL) surface observations (Miller et al., 2014). 


\section{Satellite tropospheric ammonia observations}

The main governing satellite sensor characteristics for detecting ammonia in the infrared are the measurement noise, spectral resolution, and local overpass sampling time (as the thermal contrast is tightly correlated with the diurnal cycle). This section details the CrIS instrument specifications pertinent to ammonia observations, plus a summary of comparable FTS IASI and TES sensor specifications and corresponding ammonia measurement characteristics.

\section{Relevant instrument characteristics}

\subsection{Cross-track Infrared Sounder (CrIS)}

CrIS is in a sun-synchronous orbit $(824 \mathrm{~km})$ with a mean local daytime overpass time of 13:30 in the ascending node, and a mean local nighttime overpass time of 01:30 in the descending node. CrIS provides soundings of the atmosphere over three wavelength bands in the infrared. For retrieved ammonia we focus on the $9.14-15.38 \mu \mathrm{m}\left(650-1095 \mathrm{~cm}^{-1}\right)$ range, as the main $\mathrm{NH}_{3}$ infrared absorbing spectral region is between 960 and $970 \mathrm{~cm}^{-1}$. In this spectral region CrIS's spectral resolution is $0.625 \mathrm{~cm}^{-1}$ (Tobin, 2012). CrIS is an across-track scanning instrument with a $2200 \mathrm{~km}$ swath width $\left( \pm 50^{\circ}\right)$ with the total angular field of view consisting of a $3 \times 3$ array of circular pixels of $14 \mathrm{~km}$ diameter each (nadir spatial resolution). While the spectral and spatial resolution of CrIS is less fine than that of TES, its across-track scanning swath provides a greater spatial coverage which is more similar to IASI. CrIS, with a spectral resolution similar to IASI, and $\sim 4$ times decrease in spectral noise $(\sim 0.04 \mathrm{~K}$ at $280 \mathrm{~K}$ ) in the ammonia spectral region (Zavyalov et al., 2013), has the potential to detect smaller $\mathrm{NH}_{3}$ concentrations than is currently possible with IASI. For example, the Clarisse et al. (2010) sensitivity study showed that "a reduction of the IASI noise by a factor of 2 (equally $0.1 \mathrm{~K}$ ) would significantly improve the sensitivity to $\mathrm{NH}_{3}$ and boundary sensitivity would start at zero thermal contrast during the daytime".

\subsection{Infrared Atmospheric Sounder Interferometer (IASI)}

IASI is a FTS instrument launched in a sun-synchronous orbit with overpass times of 09:30 and 21:30 mean local time. It measures thermal infrared radiation in the spectral range from $645-2760 \mathrm{~cm}^{-1}$ with a spectral resolution $0.5 \mathrm{~cm}^{-1}$ apodized and noise of $\sim 0.15-0.2 \mathrm{~K}$ at $280 \mathrm{~K}$ at $950 \mathrm{~cm}^{-1}$. IASI is a scanning instrument with a $2400 \mathrm{~km}$ swath made up of $2 \times 2$ arrays of $12 \mathrm{~km}$ diameter pixels. Under conditions of elevated ammonia and favourable thermal contrast, IASI has peak sensitivity to atmospheric ammonia in the boundary layer (Clarisse et al., 2010). Van Damme et al. (2014b) using the IASI $\mathrm{NH}_{3}$ Hyperspectral Range Index (HRI) retrieval method provide a minimum detection total column amount of $\sim 1.7 \times 10^{16}$ molec $^{-2}$ under favourable retrieval conditions (thermal contrast $\sim 10 \mathrm{~K}$ ), which is the most relevant quantity from the HRI retrieval. In a more recent overview HRI evaluation provided by Van Damme et al. (2015) they report these minimum detection total column values as corresponding to surface concentrations of $3.05 \mu \mathrm{g} \mathrm{NH}_{3} \mathrm{~m}^{-3}$ (thermal contrast of $10 \mathrm{~K}$ ) and $1.74 \mu \mathrm{g} \mathrm{NH}_{3} \mathrm{~m}^{-1}$ (thermal contrast of $20 \mathrm{~K}$ ), which for comparison purposes with CrIS (and TES) represents estimated minimum surface volume mixing ratio values of $\sim 4.3 \mathrm{ppbv}$ (thermal contrast of $10 \mathrm{~K}$ ) and $\sim 2.4 \mathrm{ppbv}$ (thermal contrast of $20 \mathrm{~K}$ ) (values extracted from supplemental Fig. R1 in Van Damme et al., 2015). These results are fairly consistent with the earlier IASI $\mathrm{NH}_{3}$ optimal estimation retrieval (which is more similar to the CrIS retrieval) results by Clarisse et al. (2010), which states that under atmospheric states with large thermal contrasts the lower bound minimum detection threshold is a profile with a surface value of $\sim 3$ ppbv.

\subsection{Tropospheric emission spectrometer (TES)}

TES has less dense spatial coverage than the scanning satellites (e.g. IASI, CrIS), but has a higher spectral resolution of $0.1 \mathrm{~cm}^{-1}\left(0.06 \mathrm{~cm}^{-1}\right.$ unapodized). TES is in a sunsynchronous orbit that has both a daytime ascending orbit with a local overpass time of 13:30 mean solar time, providing favourable conditions for high thermal contrast and thus increased sensitivity to boundary layer $\mathrm{NH}_{3}$ (Clarisse et al., 2010), and a nighttime descending orbit with a corresponding 01:30 local overpass time. The smaller satellite footprint of TES $(5 \mathrm{~km} \times 8 \mathrm{~km})$ also allows for the potential to detect more localized $\mathrm{NH}_{3}$ sources. The TES instrument has good SNR with brightness temperature noise of $\sim 0.1-0.2 \mathrm{~K}$ at $280 \mathrm{~K}$ in the $\mathrm{NH}_{3}$ region (Worden et al., 2006; Shephard et al., 2008), which is similar to IASI. It also has relative radiometric calibration that is stable over time (Connor et al., 2011), which is important for long-term trend studies. The combination of the high spectral resolution and good SNR of the TES instrument in the $\mathrm{NH}_{3}$ region provides increased sensitivity to $\mathrm{NH}_{3}$ mixing ratios near the surface from satellite observations and the selection of spectral regions (microwindows) that reduce the impact of interfering species, and consequently systematic errors in the retrievals. Shephard et al. (2011) showed that the TES $\mathrm{NH}_{3}$ retrievals have (i) a minimum detection level of $\sim 0.4 \mathrm{ppbv}$ in the representative volume missing ratio (RVMR), which corresponds to a profile with a surface volume mixing ratio of $\sim 1 \mathrm{ppbv}$, and (ii) typically have peak sensitivity in the boundary layer between $900-700 \mathrm{hPa}(1-$ $3 \mathrm{~km})$. 


\section{Retrieval strategy}

\section{1 $\mathrm{NH}_{3}$ retrieval methodology}

The ammonia retrieval strategy used here follows closely the TES $\mathrm{NH}_{3}$ retrieval approach (Shephard et al., 2011). It is based on an optimal estimation approach that minimizes the difference between the observed spectral radiances and a nonlinear radiative transfer model driven by the atmospheric state, subject to the constraint that the estimated state must be consistent with an a priori probability distribution for that state (Rodgers, 2000). If the estimated retrieved state vector, $\hat{\boldsymbol{x}}$, is close to the actual true state, $\boldsymbol{x}$, then it can be expressed through a linear retrieval as

$\hat{\boldsymbol{x}}=\boldsymbol{x}_{\mathrm{a}}+\mathbf{A}\left(\boldsymbol{x}-\boldsymbol{x}_{\mathrm{a}}\right)+\mathbf{G} \boldsymbol{n}+\mathbf{G K}_{b}\left(\boldsymbol{b}-\boldsymbol{b}_{\mathrm{a}}\right)$,

where $\boldsymbol{x}_{\mathrm{a}}$ is the a priori constraint vector. A priori information is a necessity as the retrieval is an ill-posed problem (can have many potential solutions). For these ammonia retrievals the retrieved profile values are expressed as the natural logarithm of the volume mixing ratio (VMR), since the values span many orders of magnitude in the vertical. $\mathbf{G}$ is the gain matrix (or "contribution function matrix") describing the sensitivity of the retrieval to the measurements (and thus measurement error), which maps from measurement (spectral radiance) space into retrieval space. The vector $\boldsymbol{n}$ represents the noise on the spectral radiances. The vector $\boldsymbol{b}$ contains non-retrieved parameters that affect the modelled radiance (e.g. concentrations of interfering gases) that are not included in the retrieved state vector. The $\boldsymbol{b}_{\mathrm{a}}$ holds the corresponding a priori values, and $\mathbf{K}_{b}=\partial L / \partial \boldsymbol{b}$ is the Jacobian describing the dependency of the forward model radiance $L$ on the vector $\boldsymbol{b}$. The fast forward model OSS-CrIS (Moncet et al., 2008), which is built from the Line-By-Line Radiative Transfer Model (LBLRTM) (Clough et al., 2005; Shephard et al., 2009; Alvarado et al., 2013), is used for these retrievals.

The averaging kernel, A, describes the sensitivity of the retrieval to the true state:

$\mathbf{A}=\frac{\partial \hat{\boldsymbol{x}}}{\partial \boldsymbol{x}}=\left(\mathbf{K}^{T} \mathbf{S}_{\mathrm{n}}^{-1} \mathbf{K}+\mathbf{S}_{\mathrm{a}}^{-1}\right)^{-1} \mathbf{K}^{T} \mathbf{S}_{\mathrm{n}}^{-1} \mathbf{K}=\mathbf{G K}$.

The Jacobian $\mathbf{K}$ (sometimes also called the "weighting function") describes the sensitivity of the forward model radiances to the state vector $(\mathbf{K}=\partial L / \partial \boldsymbol{x})$. The $\mathbf{S}_{\mathrm{n}}$ is the noise covariance matrix, representing the noise in the measured radiances, and $\mathbf{S}_{\mathrm{a}}$ is the a priori covariance matrix for the retrieval. For profile retrievals, the rows of $\mathbf{A}$ are functions with some finite width that give a measure of the vertical resolution of the retrieval. The sum of each row of $\mathbf{A}$ represents an estimate of the fraction of retrieval information that comes from the measurement rather than the a priori (Rodgers, 2000) at the corresponding altitude, provided the retrieval is relatively linear. The trace of the averaging kernel matrix gives the number of degrees of freedom for signal (DOFS) from the retrieval.
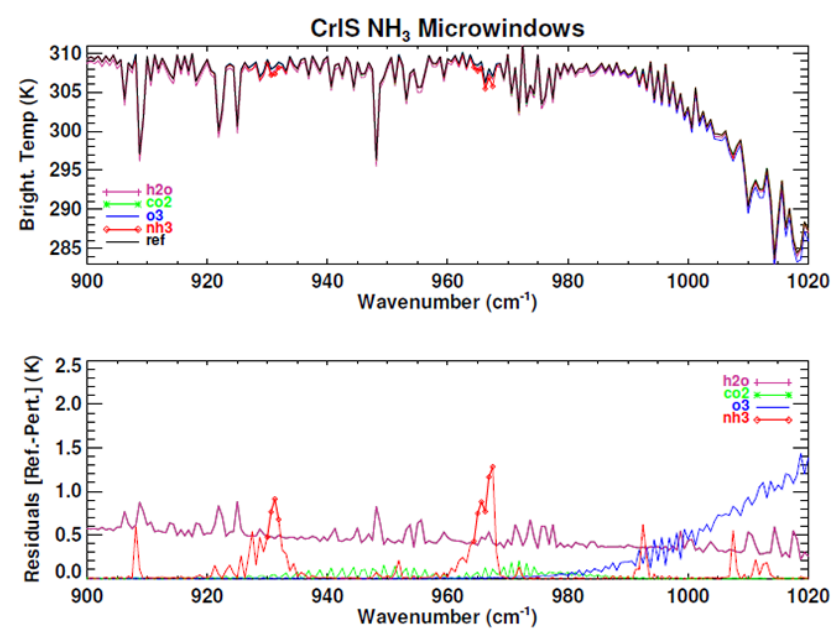

Figure 1. Plot of the CrIS spectral microwindow selection for $\mathrm{NH}_{3}$ retrievals. The top panel is the model-simulated CrIS observation for a reference atmosphere (plotted in black). Overplotted in colour are various simulated model calculations computed from the reference atmospheric profile perturbed separately by $10 \% \mathrm{H}_{2} \mathrm{O}, 10 \%$ $\mathrm{CO}_{2}, 10 \% \mathrm{O}_{3}$, and $\mathrm{NH}_{3}$ increased to a polluted profile. The bottom panel shows the residual (reference - perturbation) top of the atmosphere (TOA) brightness temperatures. The diamonds represent spectral points in the $\mathrm{NH}_{3}$ microwindows.

Implemented for these retrievals is an iterative maximum likelihood solution using the Levenberg-Marquardt method strategy (i.e. Clough et al., 1995; Rodgers, 2000):

$$
\begin{aligned}
\boldsymbol{x}^{n+1} & =\boldsymbol{x}^{n}+\left(\mathbf{K}^{T} \mathbf{S}_{\mathrm{n}}^{-1} \mathbf{K}+\mathbf{S}_{\mathrm{a}}^{-1}+\left\{\gamma \mathbf{S}_{\mathrm{a}}^{-1}\right\}\right)^{-1} \mathbf{K}^{T} \mathbf{S}_{\mathrm{n}}^{-1}[\mathbf{R}-\mathbf{L}] \\
& +\mathbf{S}_{\mathrm{a}}^{-1}\left(\boldsymbol{x}^{a}-\boldsymbol{x}^{n}\right),
\end{aligned}
$$

where $\left\{\gamma \mathbf{S}_{\mathrm{a}}^{-1}\right\}$ is the Levenberg-Marquardt term, with $\gamma$ being the Levenberg-Marquardt parameter or penalty function. $\mathbf{R}$ is the measured spectral radiance from the sensor (i.e. CrIS), and $[\mathbf{R}-\mathbf{L}]$ represents the spectral residuals being minimized in the retrieval. This numerical iterative approach is needed to account for the nonlinearities in the forward model spectral radiance calculations of the atmospheric state. Without the Levenberg-Marquardt term, this method will generally only be satisfactory for problems where the residuals are small and the initial guess is sufficiently close to the solution (linear region). Implementing the LevenbergMarquardt method provides checks when the initial guess does not satisfy this condition from one iterative step to the next, and then only minimizes the cost function over a "trust region" in which the retrieval is considered linear with respect to the step size, before proceeding to the next iteration step (Bowman et al., 2006; Moré, 1978).

\section{2 $\mathrm{CrIS} \mathrm{NH}_{3}$ microwindows}

It is often desired to perform the retrievals in spectral regions that are dominated by the species of interest. Determining the 
Table 1. Column amounts used in the CrIS simulated forward model calculations in Fig. 1.

\begin{tabular}{lcc}
\hline Molecule & $\begin{array}{c}\text { Background } \\
\left(\text { molec cm }^{-2}\right)\end{array}$ & $\begin{array}{c}\text { Enhanced } \\
\left(\text { molec cm }^{-2}\right)\end{array}$ \\
\hline $\mathrm{H}_{2} \mathrm{O}$ & $5.42 \times 10^{22}$ & $5.96 \times 10^{22}$ \\
$\mathrm{CO}_{2}$ & $8.09 \times 10^{21}$ & $8.49 \times 10^{21}$ \\
$\mathrm{O}_{3}$ & $7.35 \times 10^{18}$ & $8.08 \times 10^{21}$ \\
$\mathrm{NH}_{3}$ & $1.05 \times 10^{14}$ & $4.91 \times 10^{16}$ \\
\hline
\end{tabular}

spectral regions in which to perform the retrievals (referred to as microwindows if over small spectral domains) can depend on a number of factors. However, the general goal is to obtain the maximum amount of information content while minimizing the impact of systematic errors such as from cross-state interfering species and spectroscopic line parameters errors (laboratory measured spectroscopy lines may have different uncertainties) (Worden et al., 2004). Figure 1 shows the spectral region used for the CrIS $\mathrm{NH}_{3}$ retrievals. For the longwave infrared this is considered a relatively "clean" window region in terms of contributions from strong spectroscopic lines. However, as shown in Fig. 1, there is still the potential impact from a number of species such as $\mathrm{H}_{2} \mathrm{O}, \mathrm{CO}_{2}$ and $\mathrm{O}_{3}$ that need to be considered in terms of selection of $\mathrm{NH}_{3}$ spectroscopic retrieval regions. The column amounts used in the simulated spectrum are provided in Table 1. Utilizing microwindows can also have a practical advantage of reducing the computational burden of the high-spectral resolution forward model calculations, and the storage size of output retrieval parameters (i.e. Jacobians).

\subsection{A priori vector and constraints}

The a priori profiles (vectors) and constraints are those built for the TES $\mathrm{NH}_{3}$ retrievals (Shephard et al., 2011). In summary, both the a priori profiles and covariance matrices are derived from global distributions of $\mathrm{NH}_{3}$ from the chemical transport model GEOS-Chem (Zhu et al., 2013) for three categories of $\mathrm{NH}_{3}$ profiles:

- Polluted: represents all profiles with surface $\mathrm{NH}_{3} \geq$ 5 ppbv.

- Moderately polluted: represents all profiles with $1 \mathrm{ppbv} \geq \mathrm{NH}_{3}<5 \mathrm{ppbv}$ at the surface or $\mathrm{NH}_{3}<1 \mathrm{ppbv}$ at the surface, but $\mathrm{NH}_{3}>1 \mathrm{ppbv}$ between the surface and $500 \mathrm{hPa}$; this profile type seeks to represent those cases in which the local emissions are less than the important transport into the region.

- Unpolluted: all profiles with $\mathrm{NH}_{3}<1$ ppbv between the surface and $800 \mathrm{hPa}$.

Since the $\mathrm{NH}_{3}$ concentrations are highly variable in time and space, and not well known globally from target scene-to- scene, we followed the same two-parameter a priori selection algorithm developed for TES. The selection algorithm uses the scene SNR of the CrIS $\mathrm{NH}_{3}$ infrared spectral signature and the thermal contrast between the surface and the bottom level of the atmosphere (see Shephard et al., 2011, for further details).

\section{Comparison methodology}

One thing that needs to be considered when comparing infrared satellite inferred retrieved profiles for species with limited information, such as ammonia, is that the true vertical resolution of the retrieved parameter is often more coarse than the reported retrieval vertical levels. One of the main reasons for performing retrievals at more levels than there are independent pieces of information is to capture the vertical sensitivity as it varies from profile-to-profile depending on the atmospheric state. However, due to this "oversampling", the minor trace gas species (i.e. $\mathrm{NH}_{3}$ ) profiles often have several levels that are substantially influenced by the a priori profile (i.e. containing little information from the measurement). Depending on the purpose of the comparison, or the quantity the satellite retrieved observations are being compared against, there are a number of possible satellite comparison methods that can be implemented that take into account the true satellite retrieval sensitivity.

One approach often utilized when comparing the retrieved satellite profile, $\boldsymbol{x}_{\mathrm{c}}$, against other profiles is to "map" the comparison data to the satellite levels using a linear weighted average and to apply the satellite averaging kernel and the a priori to the mapped in situ profile:

$\boldsymbol{x}_{\mathrm{c}}^{\mathrm{est}}=\boldsymbol{x}_{\mathrm{a}}+\mathbf{A}\left(\boldsymbol{x}_{\mathrm{c}}^{\text {mapped }}-\boldsymbol{x}_{\mathrm{a}}\right)$.

This comparison approach accounts for the satellite retrieval a priori bias and the sensitivity and vertical resolution by applying the satellites averaging kernel, $\mathbf{A}$, and a priori, $\boldsymbol{x}_{\mathrm{a}}$, to the comparison profile $\boldsymbol{x}_{\mathrm{c}}^{\text {mapped }}$ (i.e. model or in situ). This method obtains an estimated profile, $x_{\mathrm{c}}^{\mathrm{ext}}$, which represents what the satellite would measure for the same air mass sampled by the in situ measurements or model. Differences between $\boldsymbol{x}_{\mathrm{c}}^{\mathrm{ext}}$ and $\hat{x}$ are presumed to be associated with the satellite measurement error on the retrieval and systematic errors resulting from parameters that were not well represented in the forward model (e.g. temperature, interfering gases, and instrument calibration), which are the latter two terms in Eq. (1). This procedure is used to compare the simulated modelled $\mathrm{NH}_{3}$ profiles with the satellite-retrieved profiles.

\section{Retrieval error analysis}

One advantage of the optimal estimation retrieval approach is that a retrieval error estimate can be computed in a 
straightforward manner based on retrieval input parameters. The total error covariance matrix $\mathbf{S}_{x}$ for a given parameter $\boldsymbol{x}$ on the retrieved levels $i$ is given by

$$
\mathbf{S}_{x}=\underbrace{(\mathbf{A}-\mathbf{I}) \mathbf{S}_{\mathrm{a}}(\mathbf{A}-\mathbf{I})^{T}}_{\text {smoothing }}+\underbrace{\mathbf{G} \mathbf{S}_{\mathbf{n}} \mathbf{G}^{T}}_{\text {measurement }}+\underbrace{\sum_{i} \mathbf{G K}_{b}^{i} \mathbf{S}_{b}\left(\mathbf{G K}_{b}^{i}\right)^{T}}_{\text {systematic }+ \text { cross state }},
$$

where $\mathbf{S}_{b}$ is the expected covariance of the non-retrieved parameter errors (Worden et al., 2004). This total error on the retrieved parameters is expressed as the sum of the smoothing (sometimes referred to as the "representation") error (first term), the measurement error (middle term), and the systematic error (last term). The smoothing error is the uncertainty due to unresolved fine structure in the profile. The measurement error is the random instrument noise in the radiance spectrum propagated to the retrieval parameter, $\boldsymbol{x}$. The systematic errors are any errors from uncertainties in the nonretrieved forward model parameters, some of which are systematic (i.e. errors in spectroscopic line parameters), and some of which change from cross-state errors propagated from retrieval-to-retrieval (i.e. interfering species). The observation error is defined as a sum of the measurement and systematic plus cross-state terms (last two terms in Eq. 5), which is useful to report when the smoothing error is accounted for in a comparison (e.g. assimilations, profile comparisons when the observational operator has been applied, see Sect. 4). Note that for this initial study we did not include any systematic errors (last term) in the total error estimates. Thus, the reported total random error covariance matrix, which is just the sum of the first two terms in Eq. (5), can be rearranged and simply written as the inverse of the Hessian $\mathbf{H}$,

$\mathbf{S}_{x}=\mathbf{H}^{-1}=\left(\mathbf{K}^{T} \mathbf{S}_{\mathrm{n}}^{-1} \mathbf{K}+\mathbf{S}_{\mathrm{a}}^{-1}\right)^{-1}$.

\section{Results}

CrIS simulations are utilized to test the algorithm development and to determine the retrieval performance capabilities and characteristics. The $\mathrm{CrIS} \mathrm{NH}_{3}$ retrieval algorithm is then applied to example CrIS observations over the San Joaquin Valley in California, USA, and compared with nearby TES satellite and quantum cascade laser (QCL) based surface observations (Miller et al., 2014).

\subsection{CrIS simulations}

To evaluate the performance of the $\mathrm{CrIS} \mathrm{NH}_{3}$ retrieval over a range of atmospheric conditions we used simulated data where the truth is known. We utilized the modelled ammonia simulated database as in Shephard et al. (2011) for the TES retrieval evaluation. This simulated data set consisted
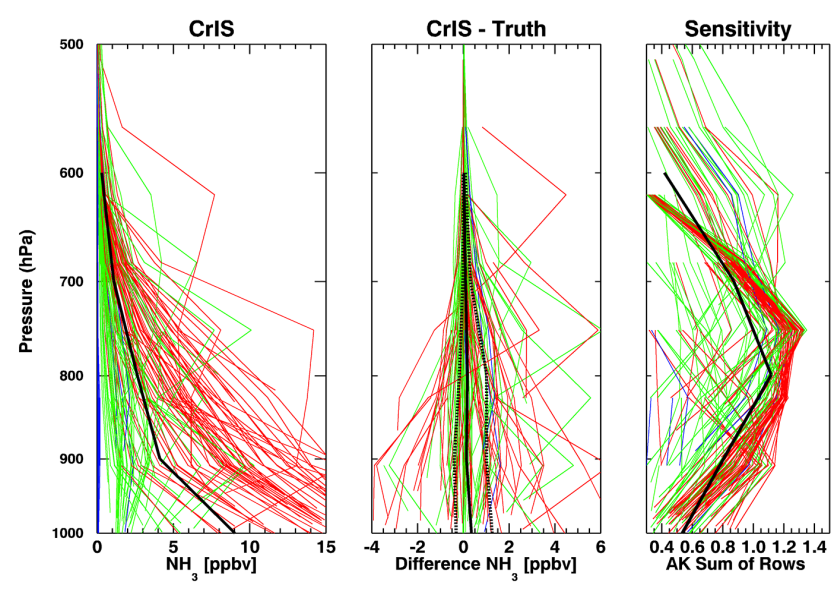

Figure 2. Simulated $\mathrm{NH}_{3}$ retrieval results over central USA from the July 2005. The thin colours indicate type of true profile: polluted (red), moderate (green), unpolluted (blue). The left panel contains the retrieved profiles, with the black solid line being the median values. The middle panel shows the profile differences (retrieved truth), where the thick solid black line is median difference and the dashed black lines are the 25 th and 75 th percent quartiles. The right panel is the sum of the rows of the averaging kernel, with the black line being the median.

of GEOS-Chem $\mathrm{NH}_{3}$ profiles (with double the $\mathrm{NH}_{3}$ emissions) that are matched up with representative atmospheric states over central USA during July 2005. In order to better expand the full retrieval space the $\mathrm{NH}_{3}$ concentrations were increased by an additional factor of 2 from the profile values in Shephard et al. (2011) and raising the number of simulated profiles to 400 . These atmospheric states were then inserted into the radiative transfer forward model to generate upwelling spectral radiances. The CrIS estimated measurement noise (random) was subsequently added to each spectrum to generate the CrIS simulated spectral radiances. These CrIS simulated spectral radiances were used with the retrieval strategy and methodology outlined in Sect. 3 in order to evaluate the capabilities of the $\mathrm{CrIS} \mathrm{NH}_{3}$ retrieval.

\subsubsection{CrIS retrieval performance}

This simulated data set produced the $\mathrm{CrIS} \mathrm{NH}_{3}$ retrieved profiles shown in Fig. 2. The maximum number of valid retrieved values from any retrieval level used in the comparison was 109. The profile comparison differences (retrieval - true) were performed using Eq. (4), which removes the influence of the retrieval a priori from the comparison. More specific statistical insight can be gained by binning the results in Fig. 2 by pressure as shown in Fig. 3. The statistics were performed on levels containing some sensitivity (sum of the rows of the averaging kernel $>0.3$ ), which is a balance between including values with the most information while still retaining enough values for reliable statistical inference. Note that, since the samples are not large and there can be 


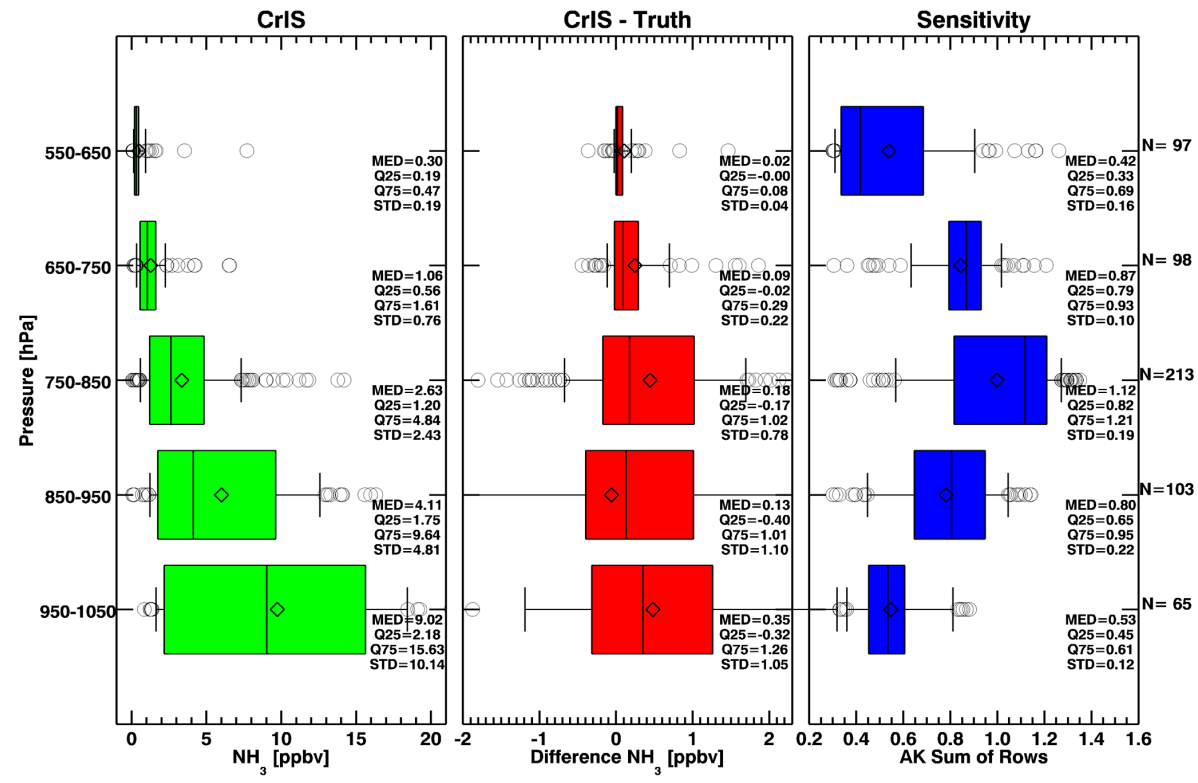

Figure 3. General characteristics for the simulated CrIS profile retrievals in Fig. 2 binned by pressure. The box edges are the 25 th and 75 th percentile, the line in the box is the median, the diamond is the mean, the whiskers are the 10th and 90th percentiles, and the circles are the outlier values outside the whiskers.

outliers, we report robust statistics that are less influenced by outliers: a median value for the bias, the interquartile range $(\mathrm{IQR}=\mathrm{Q} 75$ (75th quartile) $-\mathrm{Q} 25$ (25th quartile)) and the standard deviation (SD) derived from the robust median absolute deviation (MAD) for the variability. The CrIS retrieval strategy works well with a median bias of $\sim 6 \%$ (ranging from 3 to $8 \%$ over the pressure bins). The variability expressed in terms of IQR is $\sim 30 \%$ (on average), since the Q75 is $+26 \%$ (ranging from +14 to $+39 \%$ ) and the Q25 is $-4 \%$ (ranging from 0 to $-10 \%$ ). The variability expressed in terms of SD is $\sim 20 \%$ (on average), ranging from \pm 12 to $\pm 30 \%$ in the vertical pressure bins. These actual errors should be treated as lower bounds considering the ideal simulated conditions where the full atmospheric state besides $\mathrm{NH}_{3}$ is known perfectly. The sum of the rows of the averaging kernels in Fig. 2 show that the peak sensitivity generally ranges from $\sim 900-700 \mathrm{hPa}$, with the summary statistics in Fig. 3 showing that the $\sim 850-750 \mathrm{hPa}(\sim 1.5$ to $2.5 \mathrm{~km})$ bin (on average) has the greatest peak vertical sensitive for these simulated cases that span a large range of atmospheric states.

\subsubsection{CrIS minimum detection threshold}

Given the relatively weak atmospheric spectral signal of $\mathrm{NH}_{3}$ compared with the background infrared signal, it is also desirable to determine the minimum $\mathrm{NH}_{3}$ detection limit of CrIS. To provide some insight we took the same simulated profiles used for the CrIS retrieval performance in Sect. 6.1.1. Here we use the scene-derived SNR as a basic metric in determining the minimum detection limit with the idea that the minimum detection limit will be where the signal is just above the noise $(1<\mathrm{SNR}<2)$. The SNR is defined as the background brightness temperature minus the brightness temperature in the ammonia spectral region, divided by the noise (see Shephard et al., 2011, for more details). The $\mathrm{NH}_{3}$ infrared signal depends on both the atmospheric state conditions (i.e. thermal contrast between the surface and atmosphere) and the concentration of atmospheric ammonia. Figure 4 contains scatter plots of individual peak profile $\mathrm{NH}_{3}$ amounts, which as shown in Fig. 2 is typically the surface value, as a function of the SNR under different thermal contrast (surface - atmosphere) conditions, and as a function of the retrieval information (DOFS). Figure 5 is a summary plot of these individual retrieval points and bins them as a function of $|\mathrm{SNR}|$ with only points with positive thermal contrast included. This plot shows that in general (not the case for every retrieved profile) that increasing SNR values are associated with conditions of increased thermal contrast and increased ammonia concentrations resulting in increasing information content or sensitivity. Note that for Fig. 5 we only considered retrievals with DOFS $>0.5$ as the main purpose is to determine the minimum detectability from retrievals that contain information. Larger DOFS thresholds were tested; however, the sample size became too small to allow any statistical inference.

Here we will focus on the first bin $1 \leq \mathrm{SNR} \leq 2$ to provide some insight on the minimum detectability of $\mathrm{NH}_{3}$ by CrIS. There are a few atmospheric states that can provide profiles with peak $\mathrm{NH}_{3}$ values below 1 ppbv (i.e. 10th percentile value of $0.59 \mathrm{ppbv}, \mathrm{SNR}=1.4, \mathrm{DOFS}=0.65$, thermal contrast $=7 \mathrm{~K}$ ). However, more typical minimum 

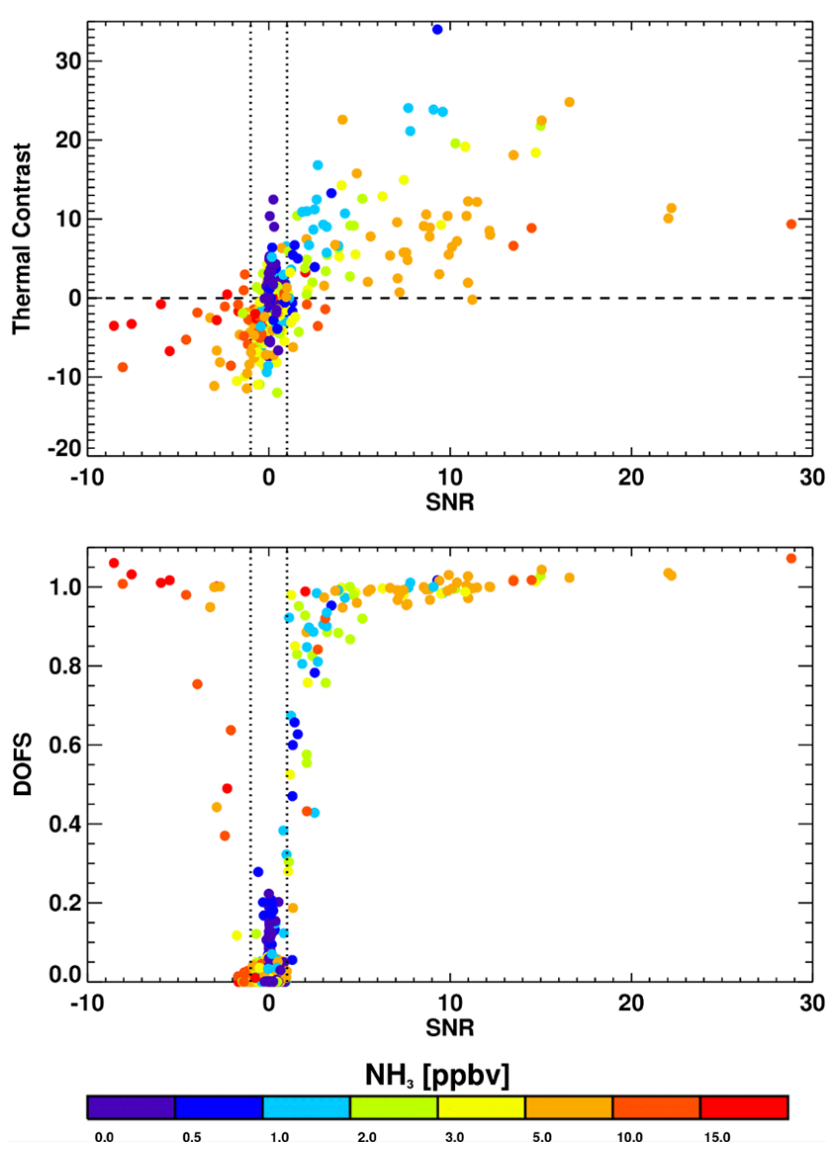

Figure 4. Using the same simulated data set as in Fig. 2 the top plot shows the SNR (difference between FM runs with and without $\mathrm{NH}_{3}$ averaged over the 966.875-967.5 window) vs. thermal contrast, colour coded by the peak value of the $\mathrm{NH}_{3}$ profile. The bottom panel shows the degrees-of-freedom-for-signal (DOFS) versus $\mathrm{NH}_{3}$ signal (SNR). The dashed lines just indicate the $\mathrm{SNR}=1$ threshold.

detection levels (still under favourable atmospheric conditions for retrievals) are provided by looking at the 25th percentile $(\mathrm{Q} 25) \mathrm{NH}_{3}$ peak profile (surface) value of $0.9 \mathrm{ppbv}$ (with $\mathrm{SNR}=1.6$, DOFS $=0.6$, thermal contrast $=5 \mathrm{~K}$ ), and the bin's median peak $\mathrm{NH}_{3}$ peak profile (surface) value of $1.2 \mathrm{ppbv}(\mathrm{SNR}=1.2, \mathrm{DOFS}=0.67$, thermal contrast $=5 \mathrm{~K})$.

\subsection{CrIS observations}

To demonstrate the applicability and further evaluate the CrIS retrieval it was then applied to real CrIS observations. For this initial study a region over the San Joaquin Valley in California, USA, was selected as this is a region of interest that is known for elevated boundary layer ammonia concentrations and spatial variability in and around the valley (e.g. Beer et al., 2008; Clarisse et al., 2010). Also, during this period there are coincident TES satellite and QCL surface observations (Miller et al., 2014) taken at the same time as NASA's Deriving Information on Surface Condi-

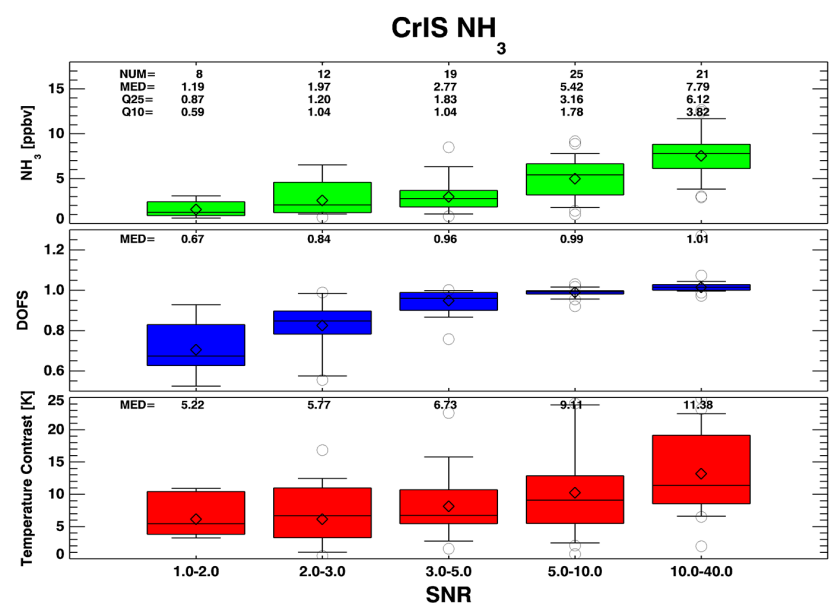

Figure 5. Box-and-whiskers plot of the simulated values from Fig. 4 for the peak NH3 profile values, measurement sensitivity (DOFS), and temperature contrast, all binned as a function of $|\mathrm{SNR}|$. The boxes edges are the 25th and 75th percentile, the line in the box is the median, the diamond is the mean, the whiskers are the 10th and 90th percentiles, and the circles are the outlier values outside the whiskers.

tions from Column and Vertically Resolved Observations Relevant to Air Quality (DISCOVER-AQ) campaign (http: //www.nasa.gov/mission_pages/discover-aq/index.html).

\subsubsection{Detailed $\mathrm{NH}_{3}$ profile retrieval example}

Here we present a detailed analysis of the CrIS measured spectrum and corresponding retrieval results from one of the elevated cases in the San Joaquin Valley region on 28 January 2013. Figure 6 contains the CrIS measured spectra in the ammonia retrieval region reported in brightness temperature. Even under elevated ammonia concentration conditions the ammonia spectral signal is only of the order of $1 \mathrm{~K}$ in brightness temperature, which is only $\sim 0.3 \%$ of the total long-wave infrared signal. Figure 6 also demonstrates how well the spectral residuals in Fig. $6 \mathrm{~b}((\mathbf{R}-\mathbf{L})$ in Eq. 3) are minimized by the retrieval in Fig. $6 \mathrm{c}$ to produce the retrieved $\mathrm{NH}_{3}$ profile in Fig. 7 (the $\boldsymbol{x}$ in Eq. 3) through the retrieval inversion.

Figure 7 contains the resulting CrIS retrieved $\mathrm{NH}_{3}$ profile and the retrieval properties from the 28 January 2013 CrIS example shown in Fig. 6. For this retrieval there is 1 piece of information (reported as the DOFS) provided by the observation. As shown by the $\mathrm{NH}_{3}$ averaging kernels, the information provided by CrIS in this example is in the profile from the surface to $600 \mathrm{hPa}$, with the peak sensitivity in the $900-800 \mathrm{hPa}$ range. The retrieved profile shows high ammonia amounts with values of $11 \mathrm{ppbv}$ at $825 \mathrm{hPa}$ where the averaging kernels show the peak CrIS retrieval sensitivity.

A nearby TES retrieval corresponding to the CrIS profile in Fig. 7 is provided in Fig. 8 for general comparison purposes. Comparing these two retrievals the TES retrieval tends 

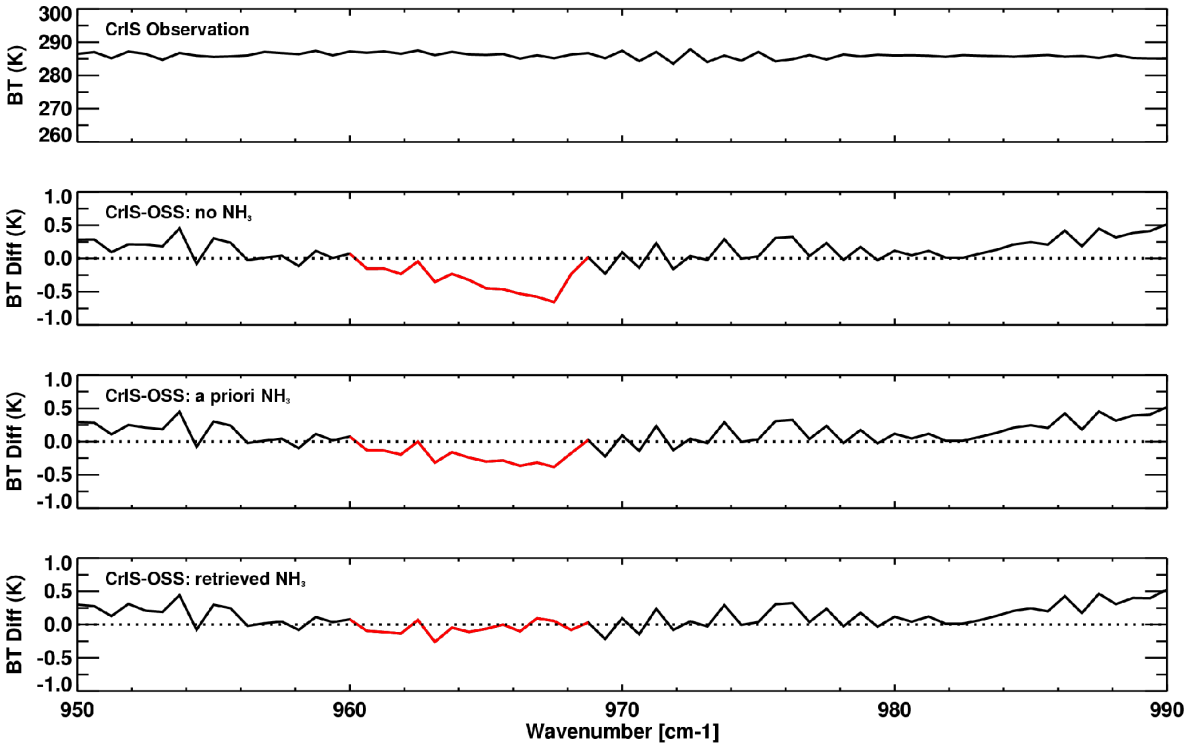

Figure 6. Top panel: Observed CrIS brightness temperature spectrum over the San Joaquin Valley ( $35.97^{\circ} \mathrm{N}, 119.28^{\circ} \mathrm{W}$ on $28 \mathrm{January} 2013$ ). Second panel from the top: Brightness temperature residuals (observed minus OSS simulation) with no $\mathrm{NH}_{3}$ included in the atmospheric profile. Third panel from the top: Brightness temperature residuals after the addition of an $\mathrm{NH}_{3}$ profile with a mixing ratio of 17.4 ppbv at $908 \mathrm{hPa}$. Bottom panel: Difference between the OSS model runs in the second and third panel from the top, showing the spectral signature of $\mathrm{NH}_{3}$ at the CrIS resolution. The red line in the residual plots highlights the spectral region used in the $\mathrm{NH}_{3}$ retrievals.

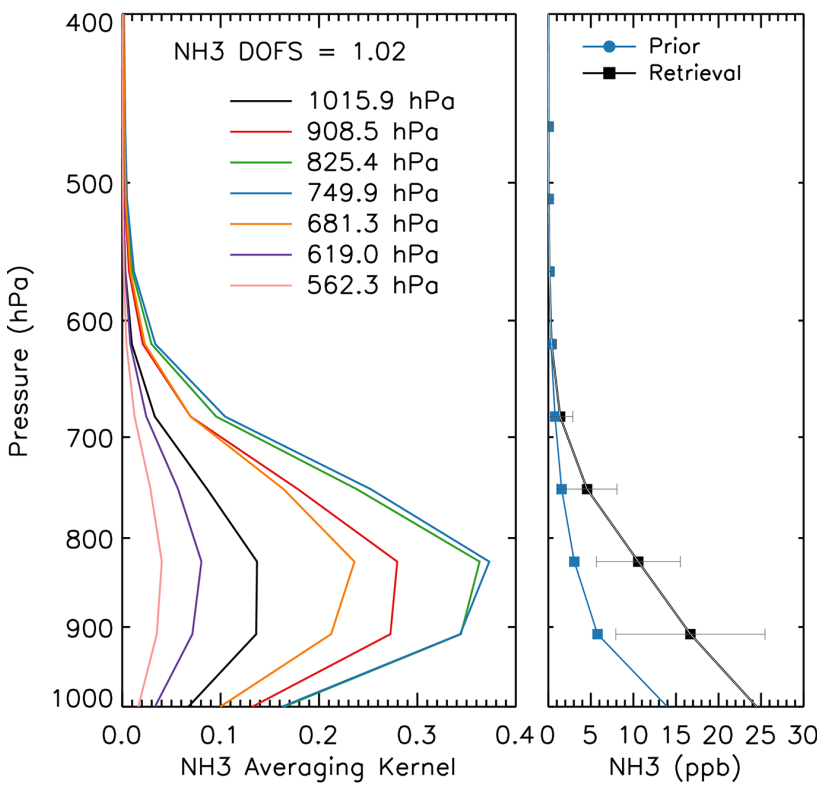

Figure 7. Averaging kernel from a CrIS retrieval from a measurement on 28 January 2013 over the San Joaquin Valley in California (left). A priori and retrieved profile with corresponding error bars are plotted in the right panel.

to have increased sensitivity lower down in the troposphere compared with the CrIS retrieval. Also, the CrIS retrieval tends to retrieve higher values of $\mathrm{NH}_{3}$ compared with the nearby TES retrieval. The estimated total retrieval errors in

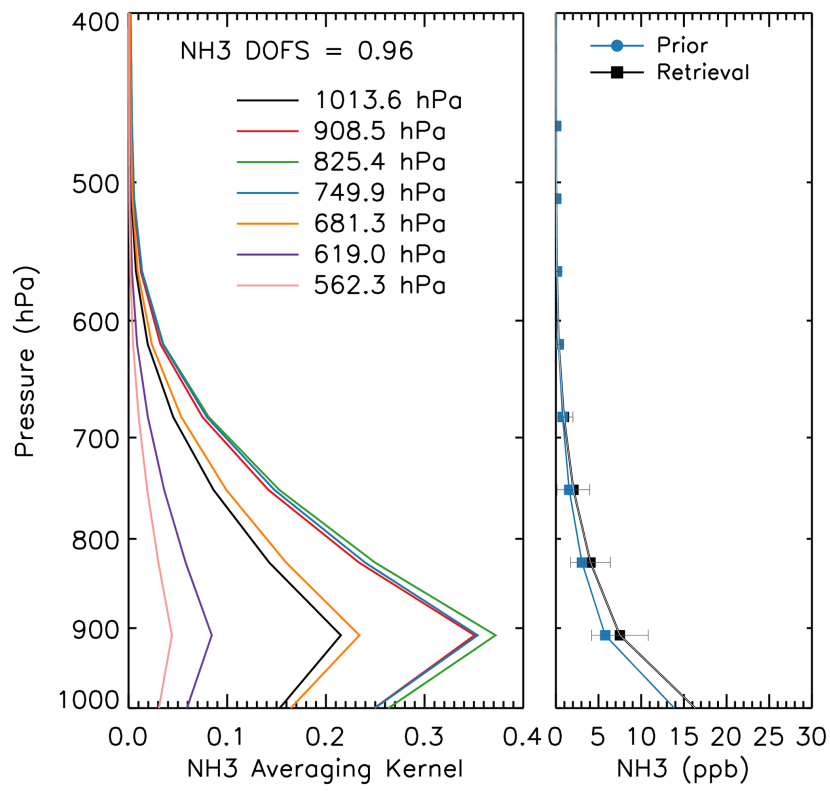

Figure 8. The TES averaging kernel and retrieved profile for the TES pixel that corresponds to the CrIS retrieval plotted in Fig. 7.

this case are relatively large at $\sim 40-50 \%$ for both the CrIS and TES retrievals. More detailed comparisons of CrIS with both TES and the QCL are provided in the following section. 


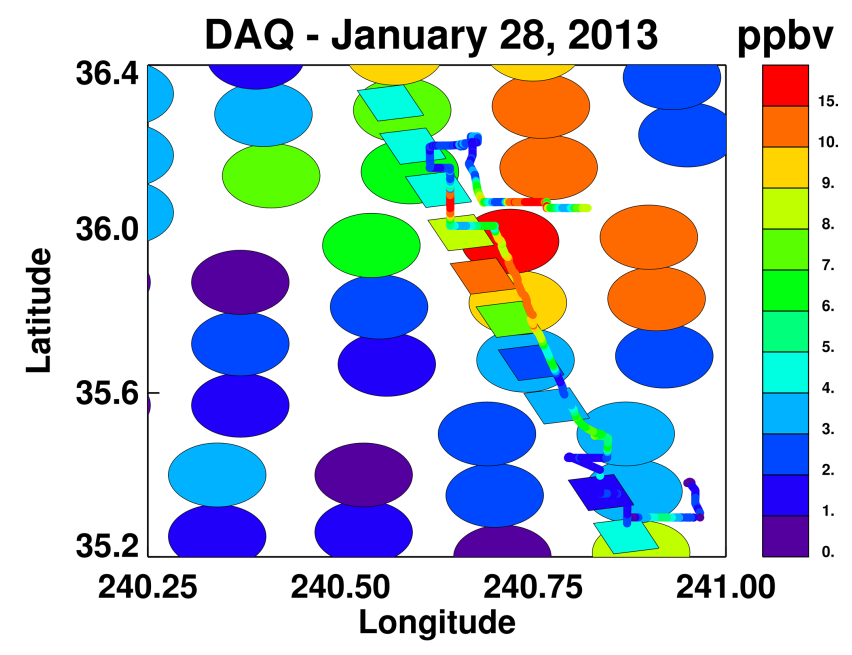

Figure 9. Map showing ammonia values from CrIS (large circles), TES (rectangles) and QCL (small circles) on 28 January 2013 during DISCOVER-AQ. The CrIS and TES satellite values are the retrieved results at $900 \mathrm{hPa}$ (peak vertical sensitivity). The QCL values are surface measurements where the values have been scaled by $1 / 6$.

\subsubsection{Central Valley comparisons with TES and QCL}

As part of the DISCOVER-AQ campaign TES performed special observations and the QCL provided in situ surface observations in the Central Valley in California, USA. On 28 January 2013 TES performed a transect (Run 16444) that consisted of 20 contiguous high spatial density $12 \mathrm{~km} \mathrm{sam}-$ ples that transected over $\sim 240 \mathrm{~km}$ section of the Central Valley from 21:24:55 to 21:27:58 UTC. During DISCOVER-AQ QCL measurements were taken to match up as close as possible to the TES transect path. The CrIS measurements are selected around the TES transect. Figure 9 contains an overlay of the CrIS (large circles), TES (rectangles) and the QCL (small circles) over the Central Valley region covered by the QCL. Since the CrIS and TES retrievals were performed with the same retrieval algorithm at the same pressure levels and with the same a priori information, for these comparisons we opted to show the satellite results from $900 \mathrm{hPa}$, which is generally the retrieval level with the peak vertical sensitivity (as shown in Fig. 10). Since the satellite and QCL measurements are sampling different parts of the lower boundary layer, direct absolute comparisons are not possible. Note that since the QCL measurements are at the surface and the satellite measurements represent boundary layer values at $\sim 1-2 \mathrm{~km}$ where the ammonia concentrations are much reduced, the QCL observations are scaled by $1 / 6$ for relative comparison purposes only. However, these relative comparisons along the transect do provide valuable insights into the performance of the satellite retrievals. Note that the large spatial fluctuations in the surface QCL $\mathrm{NH}_{3}$ observations as the instrument was driven on roads around this region closely match those seen

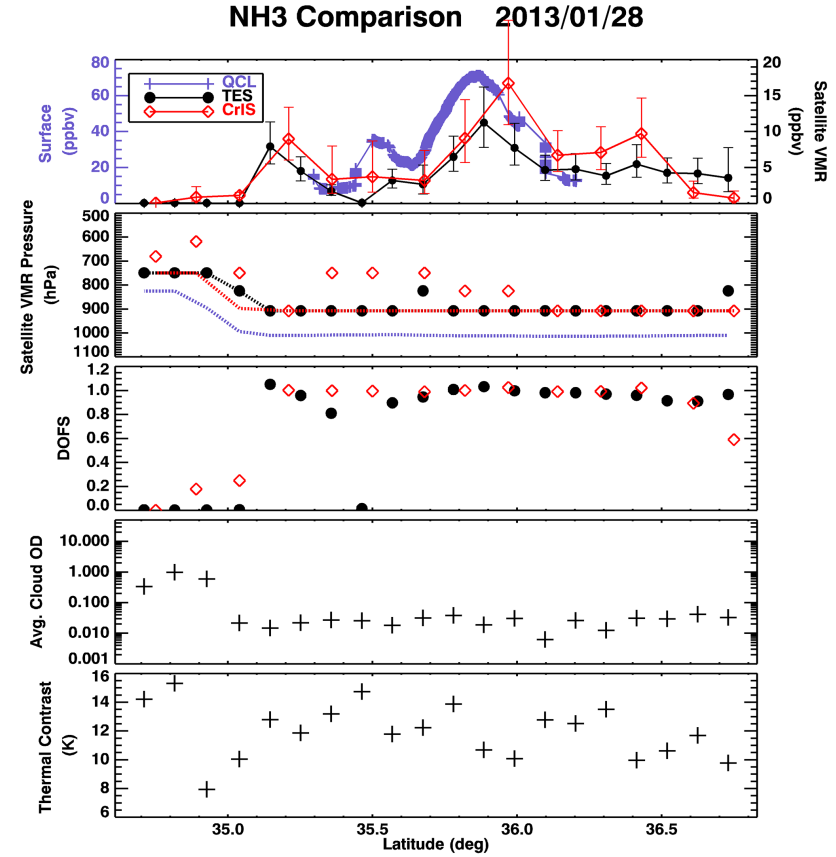

Figure 10. $\mathrm{NH}_{3}$ measurements taken on 28 January 2013 in the San Joaquin Valley in California. The top panel shows surface measurements by the Open Quantum Cascade Laser (QCL) (purple), which are averaged over the coincident TES footprint, and the satellite $900 \mathrm{hPa}$ values from the TES transect observations (black) and the corresponding closest CrIS footprints (red) with total error bars. The symbols in the second panel show the pressure of peak sensitivity for the satellite observations, with the lines indicating the pressure level of the comparison values shown in the top panel $(\sim 1 \mathrm{~km})$. The third panel contains the information content from the retrieval in terms of degrees-of-freedom for signal (DOFS). The last two panels show the atmospheric conditions in terms of cloud optical depth (COD) and thermal contrast (surface - atmosphere).

in the TES transect. The spatial map in Fig. 9 shows good agreement between all three observations in terms of general regions of higher and lower $\mathrm{NH}_{3}$ concentrations.

More details on the comparison shown in Fig. 9 are provided in Fig. 10. Here it is seen that in general the atmospheric conditions on 28 January 2013 were favourable for ammonia satellite retrievals with thermal contrasts $>6 \mathrm{~K}$, relatively high ammonia concentrations, and most of the transect sufficiently free of thick clouds. The exception is the southernmost region of the transect where the cloud optical depth (COD) approaches 1, which is sufficiently thick to block out the ammonia atmospheric signal (Shephard et al., 2011). Most of this transect had conditions that resulted in the degrees of freedom for the TES observations being $\sim 1$. The peak vertical sensitivity for the satellite retrievals under these more ideal retrieval conditions is around $1 \mathrm{~km}$ ( $900 \mathrm{hPa}$ ), with CrIS sometimes having its peak sensitivity as high as $\sim 2.5 \mathrm{~km}(750 \mathrm{hPa})$. For comparison purposes the high temporal measurements of the QCL were smoothed by 


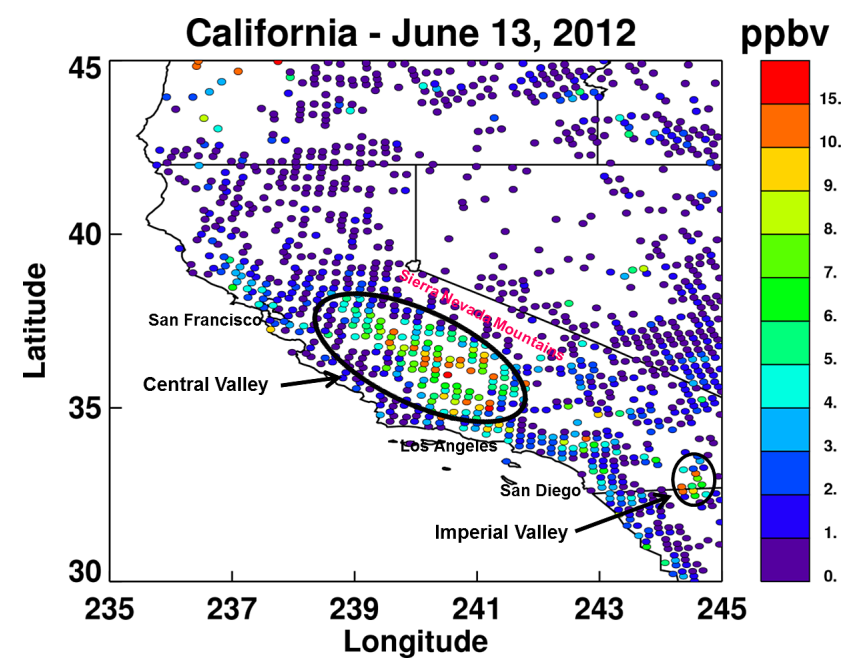

Figure 11. CrIS $\mathrm{NH}_{3}$ VMR retrievals over California, USA, on 13 June 2012. The VMR values are at the peak CrIS retrieved vertical sensitivity level based on the averaging kernels, which is typically in the boundary layer $(900-750 \mathrm{hPa}$ or $1-2.5 \mathrm{~km})$.

a running boxcar computing median values; the boxcar width matched the spatial sampling of the TES observations. Even though ammonia can be extremely variable in both space and time (as depicted by the QCL), and the horizontal and vertical sampling of the in situ and satellite observations are very different, the CrIS and TES satellite observations qualitatively capture the general variations seen in the surface in situ ammonia concentrations. Also, the TES and CrIS satellite observations themselves quantitatively agree very well and are often within the uncertainty bars of the two instruments. In general the satellite retrieved $\mathrm{NH}_{3}$ values tends to be slightly larger from CrIS than TES.

\subsubsection{Spatial distribution of $\mathrm{NH}_{3}$ over California, USA}

In order to further demonstrate the capabilities of $\mathrm{CrIS} \mathrm{NH}_{3}$ observations, retrievals were performed over the state of California, USA, on 13 June 2012 (Fig. 11). This region was selected because it contains a range of $\mathrm{NH}_{3}$ emissions with large spatial variability; there are very elevated $\mathrm{NH}_{3}$ concentrations due to anthropogenic emissions from fertilizer applications and livestock waste, as well as unpolluted nonagricultural rural regions (i.e. mountainous regions). Note that this is not the 28 January 2013 scene used in the comparisons above, as we wanted a scene with minimal cloud cover over the entire state, and the 28 January 2013 had some clouds over this larger domain. The volume mixing ratio values in Fig. 11 are from the peak sensitivity level of the CrIS retrieval, which ranges from 700 to $900 \mathrm{hPa}$. Ammonia volume mixing ratio values over the Central Valley, one of the world's most productive agriculture regions, and the Imperial Valley, which also has an economy based on agriculture, are elevated with boundary layer values in the $\sim 4-15 \mathrm{ppbv}$ range. In more rural non-agricultural regions the values are reduced to values below 2 ppbv. The white areas without any CrIS footprints have ammonia signals so low that either no retrieval was performed or the retrieval had less than 0.1 DOFS. This example demonstrates CrIS' ability to monitor the daily spatial distribution of ammonia.

\section{Conclusions}

This study presents a robust $\mathrm{CrIS} \mathrm{NH}_{3}$ retrieval that demonstrates the capabilities of utilizing CrIS to measure tropospheric ammonia. Based on both CrIS simulations and real observations there are a number of insights gained in terms of the ability of CrIS to measure tropospheric ammonia. The peak CrIS sensitivity to $\mathrm{NH}_{3}$ is typically in the range of 900 $750 \mathrm{hPa}(\sim 1.0-2.5 \mathrm{~km})$ depending on the atmospheric conditions. It has a minimum $\mathrm{NH}_{3}$ detection limit of a profile with a peak value of $\sim 1 \mathrm{ppbv}$ (typically at the surface). The retrievals have limited information content with at most one piece of information (DOFS), which provides more of an average boundary layer mixing ratio value (or a partial column type) measurement as opposed to a true atmospheric $\mathrm{NH}_{3}$ profile, which would have a number of independent pieces of information in the vertical. The information content and sensitivity varies from profile-to-profile depending on the atmospheric conditions, with increased thermal contrast and ammonia concentrations providing improved measurement sensitivity. The retrieval performance based on simulations where the truth is known shows a small positive bias of $\sim 6 \%$ with a standard deviation of $\sim \pm 20 \%$ (ranging from \pm 12 to $\pm 30 \%$ over the vertical profile). Considering that these are ideal conditions where everything except the ammonia is known perfectly, these should be considered as lower bounds on the actual errors.

Retrievals from CrIS observations on 28 January 2013 during the DISCOVER-AQ field study over the Central Valley in California, USA, correlate well with nearby QCL and TES observations. CrIS values at $\sim 1 \mathrm{~km}$ compare quantitatively very well with the TES observations, and the differences are generally within the error estimates. The CrIS ammonia distribution map over a large domain including the Central Valley (USA), demonstrates its ability to capture the expected spatial distribution in the ammonia values from elevated values in the valley from anthropogenic agriculture emissions to lower ammonia values in the unpolluted ("clean") surrounding mountainous regions.

There are a number of refinements to the retrieval strategy that will be addressed in the future to facilitate more routine global operational CrIS retrievals. Some of these potential improvements include the following: (i) accounting for impact of clouds on the $\mathrm{NH}_{3}$ retrieval (Shephard et al., 2011) either through screening, or more desirably retrieving the clouds (Kulawik et al., 2006; Eldering et al., 2008), (ii) further exploring the impact of interfering species (i.e. water 
vapour) on systematic errors on the ammonia retrieval as CrIS has a $0.625 \mathrm{~cm}^{-1}$ spectral resolution, and (iii) refinement of the CrIS surface property retrievals (i.e. surface temperature and emissivity) in the ammonia spectral region to further reduce their impact on the ammonia retrievals.

Acknowledgements. We would like to thank the DISCOVER-AQ 2013 California campaign, especially Princeton's Atmospheric Chemistry Group of Kang Sun, David Miller and Mark Zondlo, for providing the QCL surface data. Funding support for the QCL sensor is from the National Science Foundation Grant \#ECC-0540832, and the corresponding QCL validation support is provided by a NASA Earth and Space Science Fellowship \#NN12AN64H. We would also like to acknowledge the Atmospheric and Environmental Research (AER) CrIS science team for providing valuable insight in the operational CrIS observations and retrievals, in particular Richard Lynch, Gennady Uymin and Jean-Luc Moncet. This work at AER was supported under Grant \#NA130AR4310060 from the NOAA Climate Program Office (CPO) Atmospheric Chemistry, Carbon Cycle, and Climate (AC4) program.

Edited by: A. Lambert

\section{References}

Alvarado, M. J., Payne, V. H., Mlawer, E. J., Uymin, G., Shephard, M. W., Cady-Pereira, K. E., Delamere, J. S., and Moncet, J.L.: Performance of the Line-By-Line Radiative Transfer Model (LBLRTM) for temperature, water vapor, and trace gas retrievals: recent updates evaluated with IASI case studies, Atmos. Chem. Phys., 13, 6687-6711, doi:10.5194/acp-13-6687-2013, 2013.

Bash, J. O., Henze, D. K. , Zhu, L., Jeong, G.-R., Walker, J. T., Nowak, J. B., Neuman, J. A., Cady-Pereira, K. E., Shephard, M. W., Luo, M., and Pinder, R. W.: New insights into the diurnal variability of animal $\mathrm{NH}_{3}$ emissions using in situ, satellite and aloft observations, American Geophysical Union (AGU) Fall Meeting, San Francisco, CA, 12 December 2013, abstract \#A42B-06, 2013.

Bash, J., Henze, D. K., Jeong, G.-R., Zhu, L., Cady-Pereira, K. E., Shephard, M. W., Pinder, R. W., and Luo, M.: The impact of the diurnal temporal allocation of ammonia emissions on air-quality model estimates of ambient ammonia and inorganic aerosol, in preparation, 2015.

Beer, R., Glavich, T., and Rider, D. M.: Tropospheric emission spectrometer for the Earth Observing System's Aura satellite, Appl. Optics, 40, 2356-2367, 2001.

Beer, R., Shephard, M. W., Kulawik, S. S., Clough, S. A., Eldering, A., Bowman, K. W., Sander, S. P., Fisher, B. M., Payne, V. H., Luo, M., Osterman, G. B., and Worden, J. R.: First satellite observations of lower tropospheric ammonia and methanol, Geophys. Res. Lett., 35, L09801, doi:10.1029/2008GL033642, 2008.

Bowman, K. W., Rodgers, C. D., Sund-Kulawik, S., Worden, J., Sarkissian, E., Osterman, G., Steck, T., Luo, M., Eldering, A., Shephard, M. W., Worden, H., Clough, S. A., Brown, P. D., Rinsland, C. P., Lampel, M., Gunson, M., and Beer, R.: Tropospheric emission spectrometer: Retrieval method and er- ror analysis, IEEE T. Geosci. Remote Sens., 44, 1297-1307, doi:10.1109/TGRS.2006.871234, 2006.

Carfrae, J. A., Sheppard, L. J., Raven, J., Stein, W., Leith, I. D., Theobald, A., and Crossley, A.: Early effects of atmospheric ammonia deposition on Calluna vulgaris (L.) hull growing on an ombrotrophic peat bog, Water Air Soil Pollut. Focus, 4, 229-239, 2004.

Charlson, R. J., Langner, J., Rodhe, H., Leovy, C. B., and Warren, S. G.: Perturbation of the Northern-Hemisphere Radiative Balance by Backscattering from Anthropogenic Sulfate Aerosols, Tellus A, 43, 152-163, 1991.

Ciais, P., Sabine, C., Bala, G., Bopp, L., Brovkin, V., Canadell, J., Chhabra, A., DeFries, R., Galloway, J., Heimann, M., Jones, C., Le Quéré, C., Myneni, R. B., Piao, S., and Thornton, P.: Carbon and Other Biogeochemical Cycles, in: Climate Change 2013: The Physical Science Basis, Contribution of Working Group I to the Fifth Assessment Report of the Intergovernmental Panel on Climate Change, edited by: Stocker, T. F., Qin, D., Plattner, G.-K., Tignor, M., Allen, S. K., Boschung, J., Nauels, A., Xia, Y., Bex, V., and Midgley, P. M., Cambridge University Press, Cambridge, United Kingdom and New York, NY, USA, 465570, 2013.

Clarisse, L., Clerbaux, C., Dentener, F., Hurtmans, D., and Coheur, P.-F.: Global ammonia distribution derived from infrared satellite observations, Nature Geosci., 2, 479-483, doi:10.1038/ngeo551, 2009.

Clarisse, L., Shephard, M. W., Dentener, F., Hurtmans, D., CadyPereira, K., Karagulian, F., Van Damme, M., Clerbaux, C., and Coheur, P.-F.: Satellite monitoring of ammonia: A case study of the San Joaquin Valley, J. Geophys. Res., 115, D13302, doi:10.1029/2009JD013291, 2010.

Clerbaux, C., Boynard, A., Clarisse, L., George, M., Hadji-Lazaro, J., Herbin, H., Hurtmans, D., Pommier, M., Razavi, A., Turquety, S., Wespes, C., and Coheur, P.-F.: Monitoring of atmospheric composition using the thermal infrared IASI/MetOp sounder, Atmos. Chem. Phys., 9, 6041-6054, doi:10.5194/acp-9-6041-2009, 2009.

Clough, S. A., Rinsland, C. P., and Brown, P. D.: Retrieval of tropospheric ozone from simulations of nadir spectral radiances as observed from space, J. Geophys. Res., 100, 16579-16593, doi:10.1029/95JD01388, 1995.

Clough, S. A., Shephard, M. W., Mlawer, E. J., Delamere, J. S., Iacono, M. J., Cady-Pereira, K., Boukabara, S., and Brown, R. D.: Atmospheric radiative transfer modeling: a summary of the AER codes, J. Quant. Spectrosc. Radiat. T., 91, 233-244, 2005.

Connor, T. C., Shephard, M. W., Payne, V. H., Cady-Pereira, K. E., Kulawik, S. S., Luo, M., Osterman, G., and Lampel, M.: Long-term stability of TES satellite radiance measurements, Atmos. Meas. Tech., 4, 1481-1490, doi:10.5194/amt-4-1481-2011, 2011.

Crouse, D. L., Peters, P. A., van Donkelaar, A., Goldberg, M. S., Villeneuve, P. J., Brion, O., Khan, S., Atari, D. O., Jerrett, M., Pope, C. A., Brauer, M., Brook, J. R., Martin, R. V., Stieb, D., and Burnett, R. T.: Risk of Non accidental and Cardiovascular Mortality in Relation to Long-term Exposure to Low Concentrations of Fine Particulate Matter: A Canadian NationalLevel Cohort Study, Environ. Health Perspect., 120, 708-714, doi:10.1289/ehp.1104049, 2012. 
Eldering, A., Kulawik, S. S., Worden, J., Bowman, K., and Osterman, G.: Implementation of cloud retrievals for TES atmospheric retrievals: 2. Characterization of cloud top pressure and effective optical depth retrievals, J. Geophys. Res., 113, D16S37, doi:10.1029/2007JD008858, 2008.

Heald, C. L., Collett Jr., J. L., Lee, T., Benedict, K. B., Schwandner, F. M., Li, Y., Clarisse, L., Hurtmans, D. R., Van Damme, M., Clerbaux, C., Coheur, P.-F., Philip, S., Martin, R. V., and Pye, H. O. T.: Atmospheric ammonia and particulate inorganic nitrogen over the United States, Atmos. Chem. Phys., 12, 10295-10312, doi:10.5194/acp-12-10295-2012, 2012.

Kulawik, S. S., Worden, J., Eldering, A., Bowman, K. W., Gunson, M., Osterman, G., Zhang, L., Clough, S. A., Shephard, M. W., and Beer, R.: Implementation of Cloud Retrievals for Tropospheric Emission Spectrometer (TES) Atmospheric Retrievals - part I description and characterization of errors on trace gas retrievals, J. Geophys. Res., 111, D24204, doi:10.1029/2005JD006733, 2006.

Lamarque, J.-F., Bond, T. C., Eyring, V., Granier, C., Heil, A., Klimont, Z., Lee, D., Liousse, C., Mieville, A., Owen, B., Schultz, M. G., Shindell, D., Smith, S. J., Stehfest, E., Van Aardenne, J., Cooper, O. R., Kainuma, M., Mahowald, N., McConnell, J. R., Naik, V., Riahi, K., and van Vuuren, D. P.: Historical (1850-2000) gridded anthropogenic and biomass burning emissions of reactive gases and aerosols: methodology and application, Atmos. Chem. Phys., 10, 7017-7039, doi:10.5194/acp10-7017-2010, 2010.

Lamarque, J.-F., Kyle, G., Meinshausen, M., Riahi, K., Smith, S., van Vuuren, D., Conley, A., and Vitt, F.: Global and regional evolution of short-lived radiatively-active gases and aerosols in the Representative Concentration Pathways, Clim. Change, 109, 191-212, doi:10.1007/s10584-011-0155-0, 2011.

Luo, M., Shephard, M. W., Cady-Pereira, K. E., Henze, D. K., Zhu, L., Bash, J. O., Pinder, R. W., Capps, S., and Walker, J.: Satellite Observations of Tropospheric Ammonia and Carbon Monoxide: Global Distributions, Correlations and Comparisons to Model Simulations, Atmos. Environ., 106, 262-277, doi:10.1016/j.atmosenv.2015.02.007, 2015.

Miller, D. J., Sun, K., Tao, L., Khan, M. A., and Zondlo, M. A.: Open-path, quantum cascade-laser-based sensor for highresolution atmospheric ammonia measurements, Atmos. Meas. Tech., 7, 81-93, doi:10.5194/amt-7-81-2014, 2014.

Moncet, J.-L., Uymin, G., Lipton, A. E., and Snell, H. E.: Infrared radiance modeling by optimal spectral sampling, J. Atmos. Sci., 65, 3917-3934, 2008.

Moré, J. J.: The Levenberg-Marquardt algorithm: implementation and theory, Numerical Analysis (Proc. 7th Biennial Conf., Univ. Dundee, 1977), Lecture Notes in Mathematics, 630, pp. 105116, Springer, Berlin, Germany, 1978.

Myhre, G., Samset, B. H., Schulz, M., Balkanski, Y., Bauer, S., Berntsen, T. K., Bian, H., Bellouin, N., Chin, M., Diehl, T., Easter, R. C., Feichter, J., Ghan, S. J., Hauglustaine, D., Iversen, T., Kinne, S., Kirkevåg, A., Lamarque, J.-F., Lin, G., Liu, X., Lund, M. T., Luo, G., Ma, X., van Noije, T., Penner, J. E., Rasch, P. J., Ruiz, A., Seland, Ø., Skeie, R. B., Stier, P., Takemura, T., Tsigaridis, K., Wang, P., Wang, Z., Xu, L., Yu, H., Yu, F., Yoon, J.-H., Zhang, K., Zhang, H., and Zhou, C.: Radiative forcing of the direct aerosol effect from AeroCom Phase II simulations,
Atmos. Chem. Phys., 13, 1853-1877, doi:10.5194/acp-13-18532013, 2013.

Paerl, H. W., Dennis, R. L., and Whitall, D. R.: Atmospheric deposition of nitrogen: Implications for nutrient over-enrichment of coastal waters, Estuaries, 24, 667-693, 2002.

Pinder, R. W., Walker, J. T., Bash, J. O., Cady-Pereira, K. E., Henze, D. K., Luo, M., and Shephard, M. W.: Quantifying spatial and temporal variability in atmospheric ammonia with in situ and space-based observations, Geophys. Res. Lett., 38, L04802, doi:10.1029/2010GL046146, 2011.

Pope, C. A., Burnett, R. T., Thun, M. J., Calle, E. E., Krewski, D., Ito, K., and Thurston, G. D.: Lung cancer, cardiopulmonary mortality, and long-term exposure to fine particulate air pollution, J. Am. Med. Assoc., 287, 1132-1141, 2002.

Pope, C. A., Ezzati, M., and Dockery, D. W.: Fine-particulate air pollution and life expectancy in the United States, N. Engl. J. Med., 360, 376-386, 2009.

Reay, D. S., Dentener, F., Smith, P., Grace, J., and Feely, R. A.: Global nitrogen deposition and carbon sinks, Nature Geosci., 1, 430-437, doi:10.1038/ngeo230, 2008.

Reiss, R., Anderson, E. L., Cross, C. E., Hidy, G., Hoel, D., McClellan, R., and Moolgavkar, S.: Evidence of health impacts of sulfate- and nitrate-containing particles in ambient air, Inhal. Toxicol., 19, 419-449, doi:10.1080/08958370601174941, 2007.

Rodgers, C. D.: Inverse methods for atmospheric Sounding: Theory and Practice, World Sci., Hackensack, NJ, 2000.

Schwartz, J., Laden, F., and Zanobetti, A.: The concentrationresponse relation between PM2:5 and daily deaths, Environ. Health Perspect., 110, 1025-1029, 2002.

Seinfeld, J. H. and Pandis, S. N.: Atmospheric Chemistry and Physics, John Wiley, Hoboken, NJ, 1988.

Shephard, M. W., Worden, H. M., Cady-Pereira, K. E., Lampel, M., Luo, M., Bowman, K. W., Sarkissian, E., Beer, R., Rider, D. M., Tobin, D. C., Revercomb, H. E., Fisher, B. M., Tremblay, D., Clough, S. A., Osterman, G. B., and Gunson, M.: Tropospheric Emission Spectrometer Spectral Radiance Comparisons, J. Geophys. Res., 113, D15S05, doi:10.1029/2007JD008856, 2008.

Shephard, M. W., Clough, S. A., Payne, V. H., Smith, W. L., Kireev, S., and Cady-Pereira, K. E.: Performance of the line-by-line radiative transfer model (LBLRTM) for temperature and species retrievals: IASI case studies from JAIVEx, Atmos. Chem. Phys., 9, 7397-7417, doi:10.5194/acp-9-7397-2009, 2009.

Shephard, M. W., Cady-Pereira, K. E., Luo, M., Henze, D. K., Pinder, R. W., Walker, J. T., Rinsland, C. P., Bash, J. O., Zhu, L., Payne, V. H., and Clarisse, L.: TES ammonia retrieval strategy and global observations of the spatial and seasonal variability of ammonia, Atmos. Chem. Phys., 11, 10743-10763, doi:10.5194/acp-11-10743-2011, 2011.

Tobin, D.: Early Checkout of the Cross-track Infrared Sounder (CrIS) on Suomi-NPP, Through the Atmosphere, Summer 2012, available at: www.ssec.wisc.edu/news/media/2012/07/ ttasummer20121.pdf (last access date: 17 March 2015), 2012.

Van Damme, M., Clarisse, L., Dammers, E., Liu, X., Nowak, J. B., Clerbaux, C., Flechard, C. R., Galy-Lacaux, C., Xu, W., Neuman, J. A., Tang, Y. S., Sutton, M. A., Erisman, J. W., and Coheur, P. F.: Towards validation of ammonia $\left(\mathrm{NH}_{3}\right)$ measurements from the IASI satellite, Atmos. Meas. Tech. Discuss., 7, 12125-12172, doi:10.5194/amtd-7-12125-2014, 2014a. 
Van Damme, M., Clarisse, L., Heald, C. L., Hurtmans, D., Ngadi, Y., Clerbaux, C., Dolman, A. J., Erisman, J. W., and Coheur, P. F.: Global distributions, time series and error characterization of atmospheric ammonia (NH3) from IASI satellite observations, Atmos. Chem. Phys., 14, 2905-2922, doi:10.5194/acp-14-29052014, 2014b.

Van Damme, M., Clarisse, L., Dammers, E., Liu, X., Nowak, J. B., Clerbaux, C., Flechard, C. R., Galy-Lacaux, C., Xu, W., Neuman, J. A., Tang, Y. S., Sutton, M. A., Erisman, J. W., and Coheur, P. F.: Interactive comment on "Towards validation of ammonia $\left(\mathrm{NH}_{3}\right)$ measurements from the IASI satellite", Atmos. Meas. Tech. Discuss., 7, C4929-C4929, 2015.

Walker, J. M., Philip, S., Martin, R. V., and Seinfeld, J. H.: Simulation of nitrate, sulfate, and ammonium aerosols over the United States, Atmos. Chem. Phys., 12, 11213-11227, doi:10.5194/acp12-11213-2012, 2012.

Worden, J., Kulawik, S. S., Shephard, M. W., Clough, S. A., Worden, H., Bowman, K., and Goldman, A.: Predicted errors of tropospheric emission spectrometer nadir retrievals from spectral window selection, J. Geophys. Res., 109, D09308, doi:10.1029/2004JD004522, 2004.
Worden, H., Beer, R., Bowman, K., Fisher, B., Luo, M., Rider, D., Sarkissian, E., Tremblay, D., and Zong, J.: TES level 1 algorithms: Interferogram processing, geolocation, radiometric, and spectral calibration, IEEE Trans. Geosci. Remote Sens., 44, 1288-1296, doi:10.1109/TGRS.2005.863717, 2006.

Zavyalov, V., Esplin, M., Scott, D., Esplin, B., Bingham, G., Hoffman, E., Lietzke, C., Predina, J., Frain, R., Suwinski, L., Han, Y., Major, C., Graham, B., and Phillips, L.: Noise performance of the CrIS instrument, J. Geophys. Res. Atmos., 118, 1310813120, doi:10.1002/2013JD020457, 2013.

Zhu, L., Henze, D. K., Cady-Pereira, K. E., Shephard, M. W., Luo, M., Pinder, R. W., Bash, J. O., and Jeong, G.: Constraining U.S. ammonia emissions using TES remote sensing observations and the GEOS-Chem adjoint model, J. Geophys. Res., 118, 33553368, doi:10.1002/jgrd.50166, 2013.

Zhu, L., Henze, D., Bash, J., Jeong, G.-R., Cady-Pereira, K., Shephard, M., Luo, M., Paulot, F., and Capps, S.: Global evaluation of ammonia bi-directional exchange, Atmos. Chem. Phys. Discuss., 15, 4823-4877, doi:10.5194/acpd-15-4823-2015, 2015. 